common motif at Mohenjo-daro, but also it belongs to a cult as alien to Mesopotamia as is the humped bull itself. Its occurrence at Tell Agrab should point to a more than casual or commercial contact. Similarly a further link with the Mediterranean is afforded by a terra cotta relief from a small shrine at Tell Asmar, in which one of the figures, possessing one eye only, and associated with fire, is identified as a cyclops. It is interesting to note how many of the interesting series of finds recorded this year by Dr. Frankfort, such as the bowls which had contained a live snake, are to be referred to cults, popular or otherwise, upon which at present we have no information.

\section{Systematists and Text-Books}

Is a recent issue of the Nederlandsch Tijdschrift voor Geneeskunde (80, 15, pp. 1675-1677; 1936), Dr. L. D. Brongersma directs attention to the deplorable results which can arise through a lack of understanding of the principles of systematic zoology and zoological nomenclature. As an example of his thesis, Dr. Brongersma surveys the most recent edition of a standard text-book of vertebrate comparative anatomy. The confusion to the student which must arise through different authors using different names for the same animal can scarcely be avoided until the systematists have set their house in order, but there can be no possible excuse for the use of two or more names for the same creature within a single chapter; yet that has happened on numerous occasions. Perhaps even more inexcusable are errors arising from the careless confounding of similar names of very different animals. Dr. Brongersma finds that Hemidactylus (a gecko) appears amongst the Urodeles, due to confusion with Hemidactylium, and Neomeris (intended for a porpoise, but strictly applicable to a polyzoan) is confused with a tortoise and is discussed as a reptile! Further difficulties are due to faulty transcription and proof-reading, which have produced a crop of apparently new names, such as Chelonia speciosa written instead of Chelonia $s p$. and Gecko vertie intended as an abbreviation of Gecko verticillatus. The evils attendant on nomenclatorial changes can certainly be minimized by closer co-operation between teachers of zoology and systematists and by a better understanding of the difficulties which confront the latter in the search for stability. It is consequently gratifying to learn that, as a result of Dr. Brongersma's article, a list of corrigenda will be published in the next volume of the particular work he has criticized, and this will itself be submitted to competent systematists before publication.

\section{A Fire in the Mersey Tunnel}

Some of those who have driven through the three miles long Mersey Tunnel may have thought that it was unnecessary to place fire alarms at distances of fifty yards apart throughout the tunnel and to take the many other special precautions against fire which are described in guide books. Remembering that it cost eight million pounds to build and that 5,000 vehicles per hour use the tunnel, it was necessary to take every precaution. The first test of the fire alarm installation occurred on July 25 , when a lorry carrying cinematograph films from Liverpool to Birkenhead burst into flames inside the tunnel. The driver at once gave the alarm from one of the firealarm boxes, and in less than five minutes the Liverpool and Birkenhead fire brigades had put out the fire. An alarm given at any one of the ninety. eight special boxes is received at both the brigade headquarters. At the same time, large neon 'stop' signs on the roof close the tunnel to traffic, and the pay boxes at each entrance are warned by bells and red lights. The 'electromatic' vehicle-actuated traffic signals are automatically interlocked and allow vehicles to leave and prevent them from entering the affected portions of the tunnel. The alarm is also given to the ventilation control room, from which the large electric air fans can be regulated to meet requirements of any situation that may arise.

\section{The Economics of Railway Electrification}

THE Engineer of July 17, 24 and 31 contains three short articles on main-line electrification abroad, which are devoted to a statistical survey of the financial aspect of electrification. That electric traction has great advantages for suburban traffic and where water-power is plentiful and coal dear is generally admitted, but the fact that only $2 \frac{1}{2}$ per cent of the total railway mileage in the world is electrified will, perhaps, come as a surprise to those who advocate the adoption of electrification on a wide scale in Great Britain. Of all European countries, in only one, Switzerland, does electrified mileage predominate, and in only six out of twenty does it exceed trifling proportions. Commenting on this, the Engineer says : "It is impossible to believe that this neglect of electrification is due to the supineness and conservatism of so many nations. When it is observed that the German national railway system is only electrified to less than 4 per cent, those who are firmly convinced that there is no more technically progressive nation in the universe will have to admit that the arguments against electrical operation must have been overpowering." Electric traction is undoubtedly an extremely efficient means of transport, but against this has to be put the very high capital costs involved. The arguments against electrification have also been strengthened by the great improvements recently made in steam locomotives and the introduction of Diesel-electric units.

\section{German Road Progress}

Aцtнough it is only two years since Munich enter. tained the seventh International Road Congress, the city is holding another road congress and in addition a large exhibition of road building machinery on September 16-27. The Research Department of the German State Highways Commission and the leading road construction firms are in charge of all the arrangements. In Roads and Road Construction of August 1, Dr. Otto Reismann outlines the programme for the Congress. He points out that the 